\title{
Rancang Bangun Iklan Web Banner Clothing Menggunakan Google Web Designer Pendekatan Metode Design Sprint
}

\author{
Fajri Rahma Pratiwi ${ }^{1}$, Anung Rachman ${ }^{2}$ \\ ${ }^{1,2}$ Fakultas Seni Rupa dan Desain, Program Studi Desain Komunikasi Visual, Institut Seni Indonesia Surakarta, \\ Surakarta, Indonesia \\ Email: ${ }^{1}$ fajrirahmapratiwi@gmail.com, ${ }^{2}$ anung@isi-ska.ac.id
}

\begin{abstract}
Abstrak-Internet dapat digunakan sebagai media untuk melakukan bisnis dengan membangun sebuah website yang mempermudah dalam strategi promosi dan informasi produk. Tidak dapat disangkal bahwa tampilan sebuah situs web yang menarik dan mudah untuk digunakan akan lebih banyak dikunjungi orang. Agar tujuan akhir dari situs web tersebut dapat tercapai yaitu produk dapat dilirik oleh masyarakat luas melalui iklan web yang akan dirancang. merupakan ringkasan singkat dari makalah untuk membantu pembaca cepat memastikan tujuan penelitian dan sesuai dengan kebutuhan penelitian. Spanduk web adalah bentuk iklan yang dipakai di jaringan Internet. Bentuk iklan menarik perhatian ke penjelajah supaya tertarik mengunjungi situs web yang dimaksud. Spanduk ini biasanya dibuat menggunakan format gambar (JPG, GIF, PNG), skrip java dan objek multimedia lainnya. Spanduk modern bahkan sudah disertai penemuan suara dan animasi sehingga terlihat lebih menarik. Ada berbagai ukuran yang dipakai pada iklan mulai dari yang sangat kecil, melebar, memanjang hingga ada yang melintang. Y.S.I.Y (Your Smile Is Yours) usaha berbasis clothing yang dibuat pada tahun 2020 Semua artikel yang dibuat memiliki arti dan tujuan untuk lebih menyayangi diri sendiri dengan ilustrasi beraliran Pop Art. Pangsa pasar yang dituju adalah pegiat seni jalanan, olahraga jalanan dikalangan anak muda seperti Skateboard hingga komunitas sepeda $B M X$. Menggunakan sablon kualitas plastisol premium dan kaos kualitas cotton combed 30s. Rancang bangun iklan web banner pada penelitian yang sedang dirancang ini menggunakan pendekatan metode design sprint. . Pada metode design sprint dibagi menjadi 2 (dua) bagian yaitu design sprint planning dan design sprint phases and methods. Setiap bagian utama design sprint dapat dicabangkan kembali ke dalam langkah atau tahapan yang terstruktur. Metode design sprint merupakan metode yang tepat karena merancang ulang desain ini berfokus agar pengguna mengetahui semua fitur yang bisa lebih memanjakan pengguna, dengan kata lain, metode design sprint merupakan metode yang sangat komunikatif dan juga interaktif untuk mengeluarkan semua ide, inspirasi, kreativitas, hingga masalah yang ada, solusi kemudia diwujudkan ke dalam prototype dan harus divalidasi ke calon pengguna atau target pengguna yang telah ditentukan.
\end{abstract}

Kata Kunci: Rancang bangun, Iklan, Pakaian, Promosi, Situs web

Abstract - Internet can be used as a medium to do business by building a website that makes it easier to promote strategies and product information. There is no denying that the appearance of a website that is attractive and easy to use will attract more people to visit. So that the ultimate goal of the website can be achieved, namely the product can be glimpsed by the wider community through a web ad that will be designed. $\mathrm{b}$ is a short summary of the paper to help the reader quickly determine the research objectives and according to research needs. A web banner is a form of advertising used on the Internet. This form of advertising attracts the attention of explorers to visit the website in question. These banners are usually created using image formats (JPG, GIF, PNG), java scripts and other multimedia objects. Modern banners are even accompanied by sounds and animations so they look more attractive. There are various sizes used, ranging from very small, wide, elongated to some transverse. Y.S.I.Y (Your Smile Is Yours) clothing-based business created in 2020 All articles made have meaning and purpose to love yourself more with Pop Art style illustrations. The target market is street art activists, street sports among young people such as skateboarding to the BMX bicycle community. Using premium quality plastisol screen printing and cotton combed 30 s quality t-shirts. The design of the web banner ad in this research that is being designed uses the design sprint method approach. . The design sprint method is divided into 2 (two) parts, namely design sprint planning and design sprint phases and methods. Each major part of the design sprint can be branched back into structured steps or stages. The design sprint method is the right method because redesigning this design focuses on letting users know all the features that can pamper the user more, in other words, the design sprint method is a very communicative and interactive method to bring out all ideas, inspiration, creativity, to problems. the existing solution, the solution is then realized into a prototype and must be validated to potential users or predetermined target users.

Keywords: Plan, Advertising, Clothing, Promotion, Website

\section{PENDAHULUAN}

Dewasa ini internet tidak hanya digunakan untuk memperoleh informasi saja, dengan kata lain dapat digunakan sebagai media untuk melakukan bisnis dengan membangun sebuah website. Mengenai bisnis ini dilakukan penjualan produk seperti, barang-barang berbagai macam roti dan kue, hingga makanan dan minuman, dan lainnya. Sebelum mengenal internet para penjual hanya mengiklankan suatu perusahaan melalui mulut ke mulut. Penyebaran brosur hingga surat kabar sehingga hanya sedikit orang yang mengenalnya. Kini dengan hadirnya internet, kita dapat melakukan bisnis lebih mudah [1]. Suatu perusahaan tentunya harus ditunjang dengan strategi pemasaran yang baik. Keberhasilan suatu produk dalam menguasai pasar sangat tergantung kepada promosi yang dikalkulasikan oleh produsennya. Salah satu cara ampuh untuk melakukan produk mereka pada masyarakat. Oleh sebab itu, saait ini iklan sudah menjadi suatu bagian penting dalam strategi pemasaran suatu perusahaan. 
Tidak dapat disangkal bahwa tampilan sebuah situs web yang menarik dan mudah untuk digunakan akan lebih banyak dikunjungi orang. Agar tujuan akhir dari situs web tersebut dapat tercapai yaitu produk dapat dilirik oleh masyarakat luas melalui iklan web yang akan dirancang. Sebuah kesan pertama yang menarik perhatian waktu pertama kali membuka sebuah halaman situs web [2]. Spanduk web (Bahasa Inggris : web banner atau banner ads) merupakan suatu bentuk iklan yang dipakai di jaringan Internet. Bentuk iklan menarik perhatian para penjelajah supaya mengunjungi situs web yang dimaksud. Spanduk ini biasanya dibuat menggunakan format gambar (JPG, GIF, PNG), skrip java dan objek multimedia lainnya. Spanduk modern bahkan sudah disertai penemuan berupa suara dan animasi sehingga terlihat lebih menarik. Ada berbagai ukuran yang dipakai, mulai dari yang sangat kecil, melebar, memanjang hingga ada yang melintang.

Menurut Pratama, Moh Tiar Arif dan Drs. Muhammad Yahya, M.Si (2019) Kebutuhan akan sandang terutama produk kaos sangatlah penting bagi masyarakat. Kaos merupakan pakaian bagian atas yang dapat menunjang kepercayaan diri dari penggunanya, dengan model yang casual dan nyaman dipakai menjadi pilihan utama bagi masyarakat yang akan berpergian santai atau sekedar dipakai di rumah. Kaos sendiri dapat dibeli dengan desain gambar yang unik sesuai dengan selera serta dengan menggunakan jasa sablon agar kaos tersebut terlihat lebih fashionable dan lebih menarik untuk dilihat tentunya, kaos sendiri didesain untuk memberikan kenyamanan kepada penggunanya dengan bahan kain yang menyerap keringat dan memberikan rasa dingin ketika digunakan. [3]

Y.S.I.Y (Your Smile Is Yours) usaha berbasis clothing yang dibuat pada tahun 2020 oleh mahasiswa multiprogram studi Fakultas Seni Rupa dan Desain Institut Seni Indonesia Surakarta yaitu Fajri Rahma Pratiwi (saya) dari Desain Komunikasi Visual, Muhammad Akmal Abdul Rozaq dan Anggit Nugroho berasal dari Seni Rupa Murni. Semua artikel yang dibuat memiliki arti dan tujuan untuk lebih menyayangi diri sendiri dengan ilustrasi beraliran Pop Art. Pangsa pasar yang dituju adalah pegiat seni jalanan, olahraga jalanan dikalangan anak muda seperti Skateboard hingga komunitas sepeda $B M X$. Menggunakan sablon kualitas plastisol premium dan kaos kualitas cotton combed 30s. Perkembangan di dunia sablon kaos selama ini telah membawa akibat yang cukup pesat dalam dunai usaha. Perusahaan dalam keberadaan sebagai unit organisasi, pada umumnya didirikan dengan tujuan untuk memperoleh keuntungan dengan menyediakan barang dan jasa yang sesuai dengan kebutuhan masyarakat. Keuntungan bisa diperoleh apabila perusahaan dapat mencapai tingkat penjualan yang maksimal. [4]

Pencapaian konsep yang telah dijabarkan sebelumnya, dibutuhkan beberapa elemen yang memperkuat konsep diatas. Elemen yang ditambahkan seperti frame pada beberapa bagian di website. Beberapa elemen pada website e-commerce seperti yang telah dijelaskan dalam teori website anatomy ada beberapa buah. Dalam penerapannya pada website e-commerce use clothing ini, penulis menggunakan 5 (lima) elemen dasar yaitu Header, Footer, Content, Logo dan Navigation. Penjelasan dari fungsi dan penempatan masing-masing elemen pendukung atau asset dalam bentuk potongan frame, foto, tombol, grais, logo (logo perusahaan, logo media sosial dan logo messenger) dan lain-lain. Untuk memudahkan dalam perancangan website, maka penulis mengelompokkan beberapa asset yang ada berdasarkan halaman dan disatukan dalam format link yang dihasilkan dari software Google Web Designer melalui format PNG, karena yang mendukung transparansi pada website dengan iklan web banner. [5]

Iklan Homepage adalah iklan halaman pertama dari suatu website atau situs web. Homepage merupakan halaman yang paling penting karena mampu memberikan kesan pertama pada konsumen saat berkunjung. Dalam pembuatan homepage web banner, penulis membuat 4 (empat) alternatif desain dan pada akhirnya dipilihkan ketigas sebagai desain web banner pada homepage web. Rancang bangun iklan web banner pada penelitian yang sedang dirancang ini menggunakan pendekatan metode design sprint. Salah satu metode yang dapat digunakan dalam rancang bangun web iklan adalah metode yang sudah sangat generic yaitu metode design sprint. Pada metode design sprint dibagi menjadi 2 (dua) bagian yaitu design sprint planning dan design sprint phases and methods. Setiap bagian utama design sprint dapat dicabangkan kembali ke dalam langkah atau tahapan yang terstruktur. Metode design sprint merupakan metode yang tepat karena merancang ulang desain ini berfokus agar pengguna mengetahui semua fitur yang bisa lebih memanjakan pengguna, dengan kata lain, metode design sprint merupakan metode yang sangat komunikatif dan juga interaktif untuk mengeluarkan semua ide, inspirasi, kreativitas, hingga masalah yang ada, solusi kemudia diwujudkan ke dalam prototype dan harus divalidasi ke calon pengguna atau target pengguna yang telah ditentukan. Menghasilkan pelayanan bagi pengguna karena kualitas sistem iklan berpengaruh secara signifikan terhadap kepuasan para pengguna aplikasi tersebut. [6] Penelitian terdahulu yang menggunakan design sprint salah satunya membahas perancangan aplikasi bimbingan skripsi berbasis mobile studi kasus pada Fakultas Ilmu Komputer Universitas Brawijaya dengan Design Sprint dapat menerima masukan pengguna dan memvalidasi lebih awal, menyelaraskan seluruh anggota tim, mengatur dengan tujuan yang jelas dan mengembangkan hipotesis dan mengujinya dengan cepat. Hasil perancangan berupa prototipe aplikasi yaitu bimbingan skripsi berbasis mobile, dengan tahap usability study dengan memberikan tugas kepada dosen dan mahasiswa agara tidak mendapatkan masalah hanya saja dengan waktu yang lebih lama agar 
terbiasa untuk menggunakannya. Untuk hasil yang memuaskan dengan melakukan pengembangan hasil dari prototipe menjadi aplikasi yang siap digunakan oleh dosen dan mahasiswa.

\section{METODE PENELITIAN}

Tahap perancangan iklan web banner clothing (Your Smile is Yours) sebagai media promosi dan informasi yang sudah dijelaskan pada bab pendahuluan menggunakan metode design sprint. Menurut prasetyo, 2019 design sprint memiliki beberapa tahapan yang akan dilakukan mulai dari studi pustaka, design sprint planning dan design sprint phases and methods [7]. Design sprint menghasilkan kerangka kerja dan metodologi yang digunakan sangat fleksibel sehingga terus mengdaptasi untuk perancangan iklan web banner dengan menggunakan poin utama Google Web Designer yang memiliki fitur aplikasi gratis pembuat HTML5 dan AMPHTML yang berfitur lengkap serta memiliki antarmuka visual dan kode yang sudah terintegrasi dengan produk Google dan platform iklan lainnya, sehingga dapat menghubungkan data, menyederhanakan alur kerja dan berkolaborasi dengan sesama tim lain.

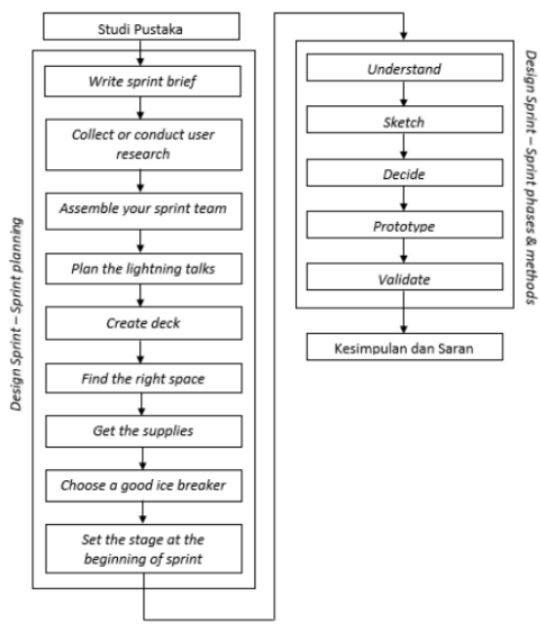

Gambar 1. Diagram alir Metodologi Penelitian

Sesuai dengan langkah-langkah pada diagram diatas, tahap perancangan iklan web banner akan lebih tertata dan berjalan sesuai dengan metode yang digunakan.

\subsection{Studi Pustaka}

Langkah awal untuk memulai metodologi Design sprint yaitu dengan tahapan studi pustaka yang memiliki tujuan sebagai pencari literatur dasar teori yang bisa didapatkan dari buku, artikel, jurnal ataupun penelitian terkait dengan perancangan iklan web banner ini. User experience merupakan semua aspek yang bertujuan mengetahui yang dirasakan oleh pengguna selama menggunakan produk clothing Your Smile is Yours hal ini bertujuan agar mengetahui bagaimana perancangan dalam membuat dan melakukan sinkronisasi elemen web banner agar tepat ke sasaran kepada pengguna produk.

Material Design Guildelines merupakan kerangka kerja tahapan yang dapat digunakan dalam perancangan tampilan antarmuka dengan kualitas tinggi yang elemennya hasil inspirasi dari benda nyata, bertujuan untuk memudahkan pengembang dalam membangun tampilan antarmuka webatau aplikasi. Metodologi design sprint merupakan kerangka kerja rapid prototyping yang dapat dilakukan validasi langkah awal untuk menghindari kegagalan produk dikemudian hari, dapat menentukan tujuan perancangan dengan cepat, memicu inovasi yang berfokus kepada para pengguna, menyelaraskan isi pekada seluruh tim untuk tercapainya suatu tujuan,

\subsection{Design Sprint (Sprint Planning)}

1. Write sprint brief : menelaah tujuan yang dapat dilakukan dan menentukan tantangan sprint yang memiliki tujuan dilakukannya penelitian ini membuat perancangan prototype iklan web banner clothing Your Smile is Yours.

2. Collect or conduct user research : melakukan wawancara kepada target pengguna clothing yaitu mahasiswa sederajat yang sedang menggandrungi kaos bermerek distro lokal.

3. Assemble your sprint team : menyatukan anggota tim yang terdiri dari 3 (tiga) orang. Yaitu : Fajri rahma Pratiwi (Designer), Anggit (Artist and stakeholder), Akmal Abdul Rozaq (Product Manager). 
4. Plan the lightning talks : menentukan topik apa yang akan dibahas saat lightning talks, dengan membandingkan produk clothing dengan tujuan untuk mendapatkan solusi yang dapat diterapkan dalam merancang iklan ini.

5. Create deck: membuat dek langkah-langkah yang ada pada tahapan setiap sprint.

6. Find the right space : mencari tempat yang cocok dan nyaman untuk melakukan sprint.

7. Get supplies : mempersiapkan kebutuhan sprint, yaitu kaos, gantungan baju, kertas, pulpen, spidol dan tentunya model.

8. Choose a good ice breaker : mengumpulkan seluruh anggota tim dan model agar membangun keakraban.

9. Set the stage at the beginning of sprint : penyusunan peraturan sebelum sprint berlangsung agar berjalan dengan lancar.

\subsection{Design Sprint (Sprint Phases and Methods)}

1. Understand

a) How might we, anggota tim mencari peluang selama lightning talks sedang membicarakan strategi perancangan web banner ini.

b) Lightning talks, melakukan presentasi tentang rancang bangun web iklan berbasis web banner yang menggunakan Google Web Designer.

c) How Might we sharing and affinity mapping, pengelompokkan hasil dari how might we setiap anggota tim dengan tema clothing dan kategori umumnya.

d) How Might we voting, melakukkan pemungutan suara pendapat yang sudah dicatat pada how might we sebelumnya.

e) User journey maping, pembuatan user journey mapping yang menjelaskan tentang perjalanan konsumen clothing agar iklan tersampaikan dengan baik.

f) User interview, melakukan wawancara dengan calon konsumen untuk mengetahui kekurangan dan kebutuhan para konsumennya.

g) Success matrix, pembuatan tahap ini untuk mengetahui kesuksesan iklan yang akan dirancang.

h) Empathy building exercise, untuk memasukan pola pikir para konsumen saat wawancara mengenai clothing.

2. Sketch

a) the warm up : comfortable, mencari peluang berdasarkan iklan yang sudah ada untuk diterapkan pada web banner clothing.

b) Boot up note taking, melakukan tinjauan ulang terkait how might we yang sudah dibuat.

c) Crazy 8's, pemungutan suara berdasarkan sketsa yang telah dibuat.

d) Solution sketch, memilih sketsa yang telah dipilih pada pemungutan pendapat

3. Decide

a) Present solution sketch, mempresentasikan solution sketch yang telah dibuat.

b) Assumption and sprint question, melakukan validasi konsep yang ada pada solution sketch.

c) Vote and select a direction, yaitu melakukan pemungutan pendapat berdasarkan sketsa yang dianggap menarik.

d) Alternate : silent review and vote, melakukan tahap ini jika tim memiliki kecenderungan sketsa yang dianggap menarik.

e) Heatmap voting, melakukan pemungutan pendapat terkait iklan atau bagian gagasan yang dianggap berdampak.

f) Decision matrix, menilai gagasan berdasarkan kriteria ataupun dampak yang akan dihasilkan.

g) Note and vote, alternatif metode dot voting untuk mengumpulkan gagasan dalam waktu 10 menit.

4. Prototype

a) Story board, menggambarkan skenario konsumen dan produsen dalam melakukan sistem jual beli.

b) Assign task, pembagian tugas kepada setiap anggota tim agar lebih jelas apa yang harus dilakukan para tahap ini.

c) Prototyping real enough, pembuatan prototype yang ada pada tahap selanjutnya akan melakukan validasi.

5. Validate

a) Usability study, wawancara kepada konsumen clothing dan memberikan promosi dari fasilitas utama untuk mengetahui tanggapan konsumen.

b) Stakeholder review, meminta pendapat terhadap stakeholder dari prototipe yang akan dibuat

c) Technical review, stakeholder designer atau product management memberikan masukan kepada prototipe yang dibuat oleh artist. 
d) Sprint conclusion : recap and next steps, peninjauan gagasan yang ditemukan selama melakukan sprint.

\section{HASIL DAN PEMBAHASAN}

Perancangan terhadap iklan web banner tentang clothing Your Smile is Yours ini menguraikan dari suatu sistem periklanan yang dibuat dengan bantuan software Google Web Designer dengan maksud sebagai media promosi sekaligus informasi agar menaikkan daya tarik konsumen dan juga berkesempatan dalam memperdalama ilmu media baru periklanan yang tidak jauh kaitannya dengan ilmu desain web. Rancang bangun untuk menciptakan suatu solusi dari masalah yang telah ditimbulkan sehingga mendapatkan hasil yang spesifik lagi dari masalah yang diteliti. setiap masalah yang akan dipecahkan harus ditemukan solusinya, fasilitas yang akan dikembangkan, penentuan jenis Bahasa pemograman dan tujuan yang tercapai dari proses pengembangan ide tersebut. Apabila proses pemecahan masalah dilakukan dengan benar maka akan dicapai hasil yang optimal juga tentunya.

\subsection{Penyiapan Data Konten}

Tahap pernacangan menjelaskan hasil prototipe konten web banner dengan menggunakan metode design sprint yang sudah dijelaskan pada metode diatas dan studi kasus yang sudah tertera pada pendahuluan yaitu perancangan iklan web banner tentang clothing pada brand Yours Smile is Yours dengan pendekatan metode design sprint. Konten yang akan dibuat yaitu terdapat 4 (empat) iklan web dengan luaran web banner dapat diuraikan sebagai berikut :

a. konten "tentang Your Smile is Yours"

data yang harus disiapkan berupa cerita dibalik terciptanya brand ini seperti bagaimana awal mula terciptanya nama hingga cerita alasan mengangkal visual pada kaos dengan luaran tematik dan terbtas disetiap edisinya.

b. Konten "Edisi 1"

Edisi 1 brand mengeluarkan 3 (tiga) desain kaos sekaligus dengan dua warna kaos yang berbeda. Data konten berupa foto produk kaos dan foto model diberi transisi yang sederhana dan warna yang menarik.

c. Konten "Edisi 2"

Edisi kedua ini merilis hanya satu desain kaos yang berwarna hitam. Data konten yang diangkat berupa foto produk yang dikenakan oleh model sesuai dengan konsep kaos yang emo dan seni.

d. Konten "Shop Now!'

Memasarkan semua edisi desain kaos yang telah diperkenalkan dari konten sebelumnya. Pada konten ini menampilkan semua cuplikan dari kedua edisi kaos Your Smile is Yours menggunakan data konten pertama hingga ketiga menghasilkan final konten yang menjadi iklan yang terakhir terlihat pada web banner.

\subsection{Konsep Iklan}

Konsep iklan dengan luaran berupa web banner pada iklan kaos yang sudah dijelaskan pada penyiapan data konten diatas terdapat 4 (empat) konten yang saling berkesinambungan satu sama lain. Seperti layaknya web series iklan ini menampilkan iklan yang berisikan informasi dan promosi secara runut dan berkelanjutan sari satu konten hingga konten yang terakhir.

a. Konten "Tentang Your Smile is Yours"

Copywriting: "Your Smile is Yours for Everything. Hadir di tengah pandemic menawarkan sebuah karya yang dapat kalian miliki, Shop Now!"

Visual : kaos polos latar belakang oranye

b. Konten "Edisi 1"

Copywriting : "Your Smile is yours for Everything. Shop Now! IDR 125K

Visual : foto produk kaos edisi satu dengan tiga desain yang berbeda dengan logo Y.S.I.Y.

c. Konten "Edisi 2"

Copywriting : "Your Smile is Yours for Everything. Grab Yours Now! IDR 125K

Visual : foto produk kaos desain edisi kedua dengan model agar lebih menarik tidak lupa indentitas brand dengan logo Y.S.I.Y.

d. Konten "Shop Now!" 
Copywriting : "Your Smile is Yours for Everything. Shop Now. Hadir di tengah pandemic menawarkan sebuah karya yang dapat kalian miliki"

Visual : gabungan antara konten edisi 1 (satu) dan edisi kedua di mana mengambil elemen grafis bingkai ungu dari edisi 1 dan foto produk diambil dari edisi kedua.

\subsection{Implementasi Elemen Grafis dan Animasi}

Implementasi iklan web banner ini juga dibuat berdasarkan rancangan yang sesuai dengan metode design sprint. Bantuan software sangat membantu dapat mengimplementasikan rancangan ini karena hasil akhir yang dibutuhkan berupa link shareable yang dapat dilihat semua orang tanpa harus membayar adsense atau semacamnya. Desain yang terdapat beberapa komponen di dalamnya menjadi bahan komunikasi konsumen melalui iklan visual yang menarik dan tepat sasaran target. Dihasilkan 4 (empat) desain web banner sebagai iklan yang berkesunambungan dan berseries berikut merupakan implementasi hasil desain web banner clothing :

\subsubsection{Konten "Tentang Your Smile is Yours"}

Elemen grafis

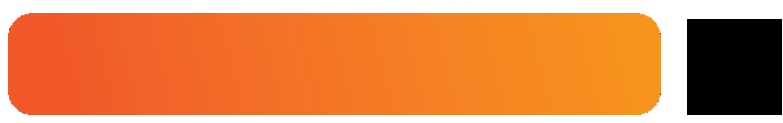

Gambar 2. Elemen Grafis Konten Tentang Your Smile Is Yours

Gaya visual yang mengikuti dengan perkembangan era digital, agar mendapatkan respon yang memuaskan sesuai dengan demografi iklan yang akan ditayangkan nanti. Memilih warna yang kontras selaras dengan logo dan juga tipografi yang akan digunakan.

Logo

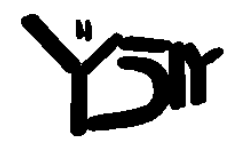

Gambar 3. Logo Konten Tentang Your Smile Is Yours

logo yang terinspirasi dari singkatan nama merek yaitu Your Smile Is Yours dengan strategi yang sederhana, menarik dan mudah diingat oleh audiens.

Tipografi

\section{hadir di tensiah pandemi menawarkan sebuah karya yang dapat kalian milliki.}

\section{SHOP NOW!}

Everything.
Your Smile is Yours for

Gambar 4. Tipografi Konten Tentang Your Smile Is Yours

Pemilihan kata yang ringan dan memberikan kesan persuasif lebih melekat di benak para audiens. Karena merek ini muncul pada saat maraknya pandemi maka audiens akan lebih mengingat merek jika kemunculannya adalah ditengah peristiwa besar.

Fotografi

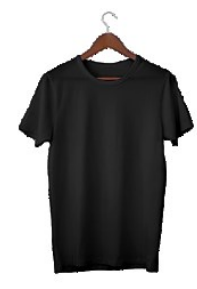

Gambar 5. Fotografi Konten Tentang Your Smile Is Yours 
Foto produk yang sesuai dengan realitas merek akan lebih menjanjikan para audiens ketimbang menggunakan foto yang sangat baik dan bagus namun tidak menyesuaikan spesifikasi merek yang sebenarnya.

Hasil Layout

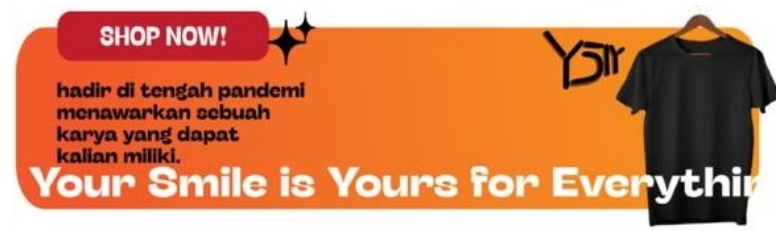

Gambar 6. Hasil Layout Konten Tentang Your Smile Is Yours

(web banner ini menggunakan ukuran 500x100px horizontal yang biasanya diletakkan di atas atau bawah web)

Animasi

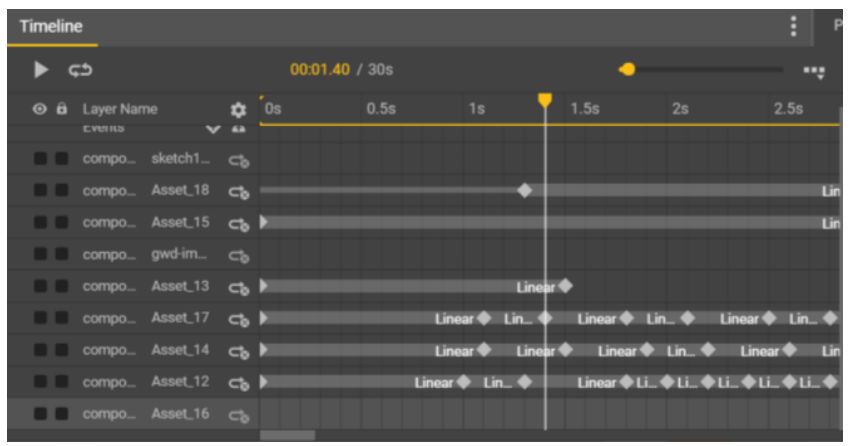

Gambar 7. Animasi Konten Tentang Your Smile Is Yours

Animasi berjalan selama 3 detik dengan beberapa animasi yang sederhana terdapat 9 komponen elemen grafis dan turunannya dengan timeline yang diberi keyframe dan fill yang berbeda memberi kesan animasi yang berkedip dan tulisan yang bergerak kesamping.

\subsubsection{Konten "Edisi 1"}

Elemen grafis

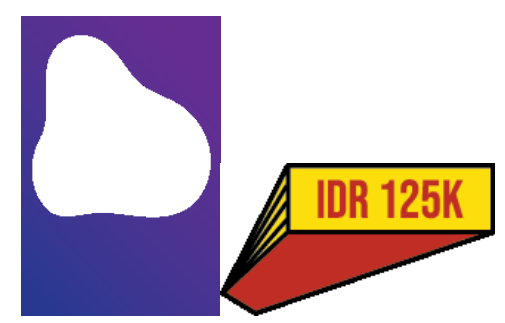

Gambar 8. Elemen Grafis Konten Edisi 1

Pemilihan gaya visual yang mengikuti dengan perkembangan era digital, agar mendapatkan respon yang memuaskan sesuai dengan demografi iklan yang akan ditayangkan nanti. Memilih warna yang kontras selaras dengan logo dan juga tipografi yang akan digunakan.

Logo

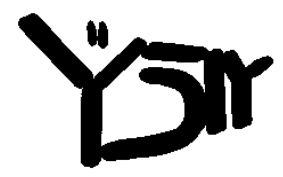

Gambar 9. Logo Konten Edisi 1 
logo yang terinspirasi dari singkatan nama merek yaitu Your Smile Is Yours dengan strategi yang sederhana, menarik dan mudah diingat oleh audiens.

Tipografi

\section{SHOP NOW!}

\section{Your Smile is Yours for Everything.}

Gambar 10. Tipografi Konten Edisi 1

Pemilihan kata yang ringan dan memberikan kesan persuasif lebih melekat di benak para audiens. Karena merek ini muncul pada saat maraknya pandemi maka audiens akan lebih mengingat merek jika kemunculannya adalah ditengah peristiwa besar.

Fotografi

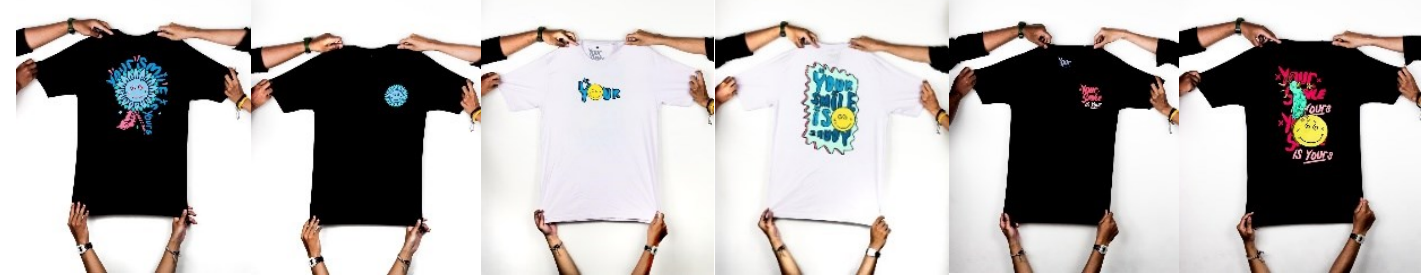

Gambar 11. Fotografi Konten Edisi 1

Menggunakan foto produk jepretan asli dari brand Your Smile is Yours berupa 3 (tiga) desain kaos dengan warna yang berbeda.

Hasil Layout

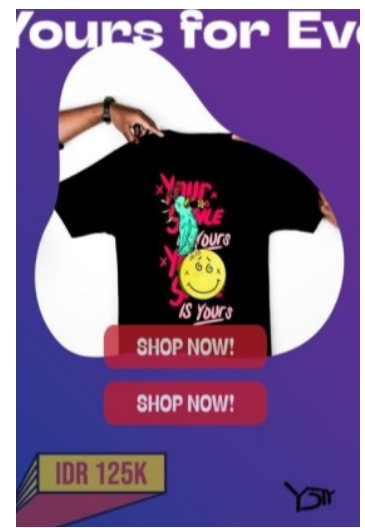

Gambar 12. Hasil Layout Konten Edisi 1

(web banner ini menggunakan ukuran 300x450px vertikal yang biasanya diletakkan di tengah web)

Animasi

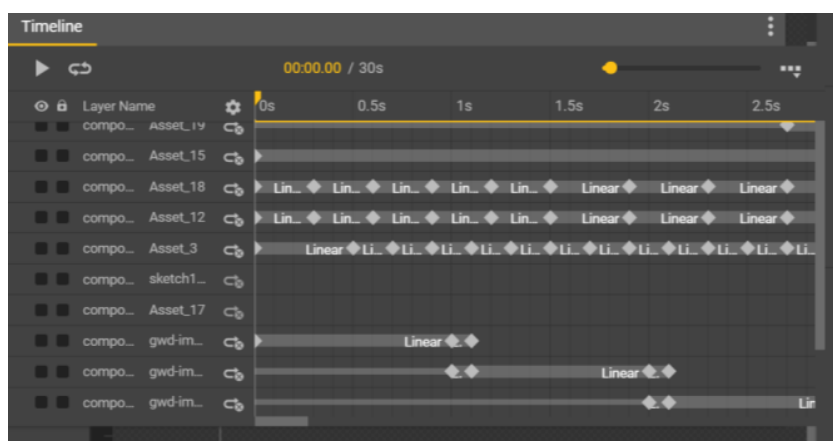

Gambar 13. Animasi Konten Edisi 1 
Animasi berjalan selama 6 detik dengan beberapa animasi yang sederhana terdapat 11 komponen elemen grafis dan turunannya dengan timeline yang diberi keyframe dan fill yang berbeda memberi kesan animasi yang berkedip dan tulisan yang bergerak kesamping. Diuraikan melalui tabel sebagai penjelas setiap detik animasi iklan sebagai berikut :

Tabel 1. Animasi Konten Edisi 1

\begin{tabular}{|c|c|}
\hline detik & penjelasan \\
\hline 01.00 & $\begin{array}{l}\text { Tipografi "Your Smile is Yours for Everything." Bergerak kesamping } \\
\text { dari detik } 00.00-06.00 \\
\text { Shot } 01.00 \text { ini menampilkan desain kaos pertama tampak depan dan } \\
\text { animasi SHOP NOW dan IDR } 125 \mathrm{~K} \text { menggunakan teknik keyframe } \\
\text { dan fill setiap } 00.50 \text { detik dan terlihat berkedip cepat. }\end{array}$ \\
\hline 02.00 & $\begin{array}{l}\text { Tipografi sama dengan shot detik ke } 01.00 \text {. } \\
\text { Shot } 02.00 \text { ini menampilkan desain kaos pertama tampak belakang } \\
\text { dan animasi SHOP NOW dan IDR } 125 \mathrm{~K} \text { menggunakan teknik } \\
\text { keyframe dan fill setiap } 00.50 \text { detik dan terlihat berkedip cepat. }\end{array}$ \\
\hline 03.00 & $\begin{array}{l}\text { Tipografi sama dengan shot detik ke } 01.00 \text { dan terbaca "is Yours" } \\
\text { Shot } 03.00 \text { ini menampilkan desain kaos kedua tampak depan dan } \\
\text { animasi SHOP NOW dan IDR } 125 \mathrm{~K} \text { menggunakan teknik keyframe } \\
\text { dan fill setiap } 00.50 \text { detik dan terlihat berkedip cepat. }\end{array}$ \\
\hline 04.00 & $\begin{array}{l}\text { Tipografi sama dengan shot detik ke } 01.00 \text { dan terbaca "Everthing" } \\
\text { Shot } 04.00 \text { ini menampilkan desain kaos kedua tampak belakang dan } \\
\text { animasi SHOP NOW dan IDR } 125 \mathrm{~K} \text { menggunakan teknik keyframe } \\
\text { dan fill setiap } 00.50 \text { detik dan terlihat berkedip cepat. }\end{array}$ \\
\hline 05.00 & $\begin{array}{l}\text { Tipografi sama dengan shot detik ke } 01.00 \text { dan terbaca "Everthing" } \\
\text { Shot } 05.00 \text { ini menampilkan desain kaos ketiga tampak depan dan } \\
\text { animasi SHOP NOW dan IDR } 125 \mathrm{~K} \text { menggunakan teknik keyframe } \\
\text { dan fill setiap } 00.50 \text { detik dan terlihat berkedip cepat. }\end{array}$ \\
\hline 06.00 & $\begin{array}{l}\text { Tipografi sama dengan shot detik ke } 01.00 \text { dan terbaca "-ything. You” } \\
\text { Shot } 06.00 \text { ini menampilkan desain kaos ketiga tampak belakang dan } \\
\text { animasi SHOP NOW dan IDR } 125 \mathrm{~K} \text { menggunakan teknik keyframe } \\
\text { dan fill setiap } 00.50 \text { detik dan terlihat berkedip cepat. }\end{array}$ \\
\hline
\end{tabular}

\subsubsection{Konten "Edisi 2"}

Elemen grafis

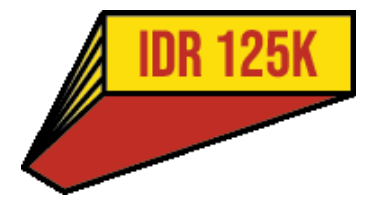

Gambar 14. Elemen Grafis Konten Edisi 2

Gaya visual yang mengikuti dengan perkembangan era digital, agar mendapatkan respon yang memuaskan sesuai dengan demografi iklan yang akan ditayangkan nanti. Memilih warna yang kontras selaras dengan logo dan juga tipografi yang akan digunakan. Pemilihan elemen grafis digunakan sebagai keterangan harga agar audiens langsung mengerti bahwa merek tersebut memiliki harga yang ekonomis.

Logo

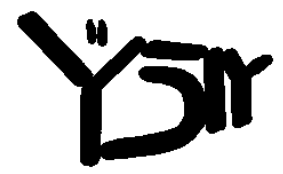

Gambar 15. Logo Konten Edisi 2 
logo yang terinspirasi dari singkatan nama merek yaitu Your Smile Is Yours dengan strategi yang sederhana, menarik dan mudah diingat oleh audiens.

Tipografi

\section{Your Smile is Yours for Everything.}

Gambar 16. Tipografi Konten Edisi 2

Pemilihan kata yang ringan dan memberikan kesan persuasif lebih melekat di benak para audiens. Karena merek ini muncul pada saat maraknya pandemi maka audiens akan lebih mengingat merek jika kemunculannya adalah ditengah peristiwa besar.

Fotografi

Menggunakan foto produk jepretan asli dari brand Your Smile is Yours.

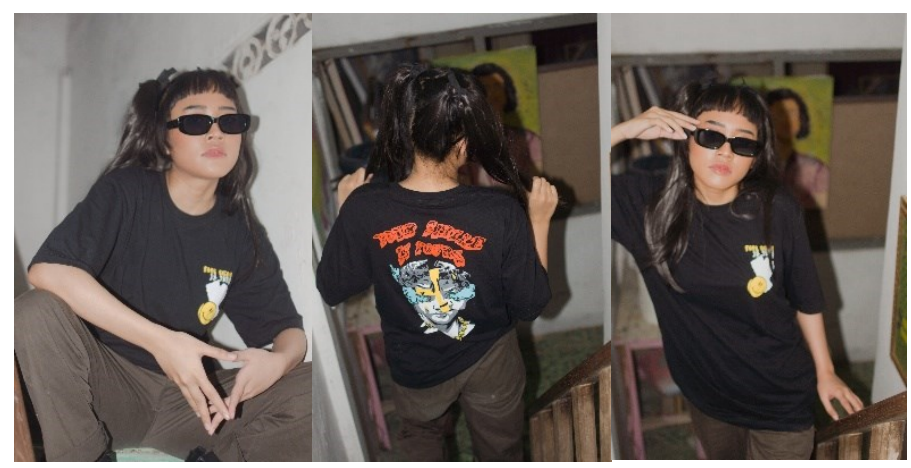

Gambar 17. Fotografi Konten Edisi 2

Menggunakan foto produk jepretan asli dari brand Your Smile is Yours berupa desain kaos dengan warna hitam, pemilihan model yang sesuai dengan citra merek yang dibangun.

Hasil Layout

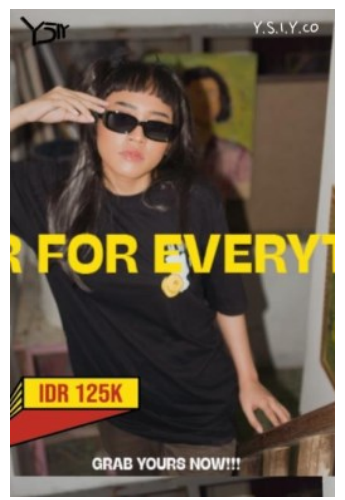

Gambar 18. Hasil Layout Konten Edisi 2

(web banner ini menggunakan ukuran 300x450px vertikal yang biasanya diletakkan di tengah web)

Animasi 


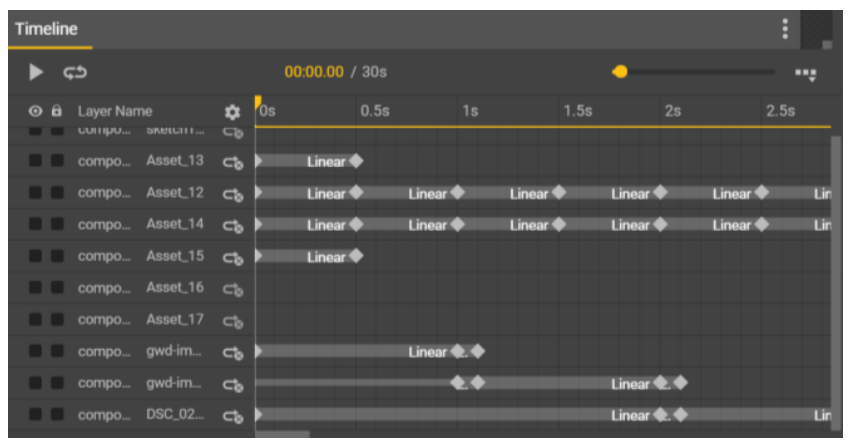

Gambar 19. Animasi Konten Edisi 2

Animasi berjalan selama 3 detik dengan beberapa animasi yang sederhana terdapat 8 komponen elemen grafis dan turunannya dengan timeline yang diberi keyframe dan fill yang berbeda memberi kesan animasi yang berkedip dan tulisan yang bergerak kesamping dengan ukuran 400x500px Diuraikan melalui tabel sebagai penjelas setiap detik animasi iklan sebagai berikut :

Tabel 2. Animasi Konten Edisi 2

\begin{tabular}{|l|l|}
\hline Detik & penjelasan \\
\hline 01.00 & $\begin{array}{l}\text { Fotografi yang diberi transisi bergeser keatas dengan } \\
\text { cepat selama 01.00 detik } \\
\text { Tipografi yang bergeser kesamping dengan tulisan } \\
\text { berwarna kuning kontras dengan latar belakang } \\
\text { fotografi tersebut. }\end{array}$ \\
\hline 02.00 & $\begin{array}{l}\text { Transisi fotografi yang cepat terlihat web banner } \\
\text { yang sesuai dengan konsep brand yang atraktif dan } \\
\text { artsy. }\end{array}$ \\
\hline 03.00 & $\begin{array}{l}\text { Transisi bergeser keatas fotografi terakhir terlihat } \\
\text { model yang menghadap kebelakang memperlihatkan } \\
\text { desain kaos yang menjadi ciri khas pada edisi kedua } \\
\text { ini. }\end{array}$ \\
\hline
\end{tabular}

\section{4 konten "Shop Now!”}

Elemen grafis
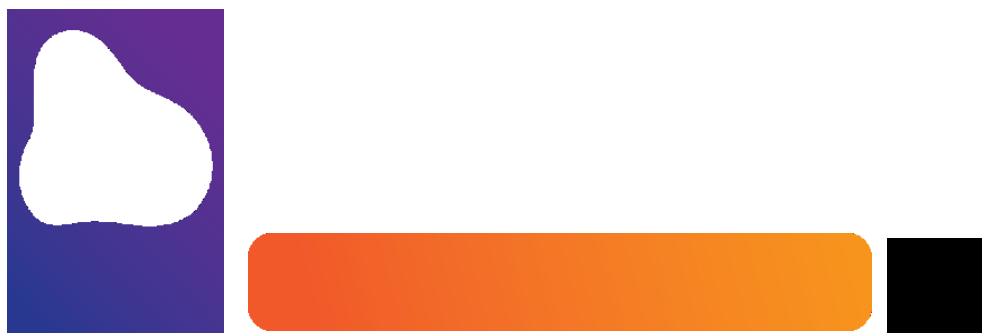

Gambar 20. Elemen Grafis Konten Shop Now

Gaya visual yang mengikuti dengan perkembangan era digital, agar mendapatkan respon yang memuaskan sesuai dengan demografi iklan yang akan ditayangkan nanti. Memilih warna yang kontras selaras dengan logo dan juga tipografi yang akan digunakan.

Logo

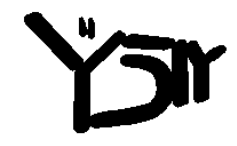

Gambar 21. Logo Konten Shop Now 
logo yang terinspirasi dari singkatan nama merek yaitu Your Smile Is Yours dengan strategi yang sederhana, menarik dan mudah diingat oleh audiens.

Tipografi

\section{hadir di tengah pandemi menawarkan sebuah karya yang dapat kallan milliki.}

\section{SHOP NOW!} Your Smile is Yours for

Gambar 22. Tipografi Konten Shop Now

Pemilihan kata yang ringan dan memberikan kesan persuasif lebih melekat di benak para audiens. Karena merek ini muncul pada saat maraknya pandemi maka audiens akan lebih mengingat merek jika kemunculannya adalah ditengah peristiwa besar.

\section{Fotografi}

Menggunakan foto produk jepretan asli dari brand Your Smile is Yours

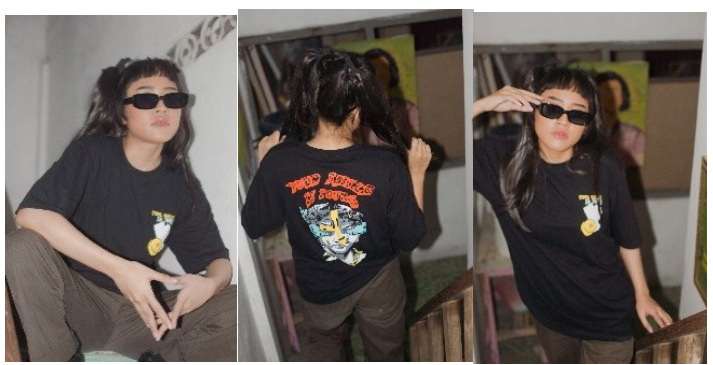

Gambar 23. Fotografi Konten Shop Now

Menggunakan foto produk jepretan asli dari brand Your Smile is Yours berupa desain kaos dengan warna hitam, pemilihan model yang sesuai dengan citra merek yang dibangun.

Hasil Layout

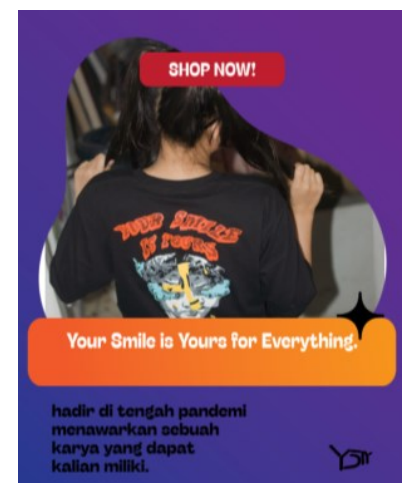

Gambar 24. Hasil Layout Konten Shop Now

(web banner ini menggunakan ukuran 300x450px vertikal yang biasanya diletakkan di tengah web)

Animasi 


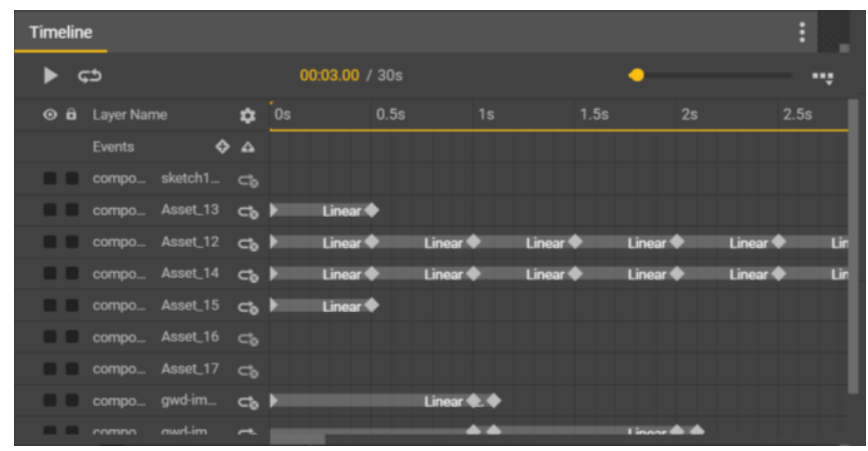

Gambar 25. Animasi Konten Shop Now

Animasi berjalan selama 3 detik dengan beberapa animasi yang sederhana terdapat 9 komponen elemen grafis dan turunannya dengan timeline yang diberi keyframe dan fill yang berbeda memberi kesan animasi yang berkedip dan tulisan yang bergerak kesamping dengan ukuran 400x500px Diuraikan melalui tabel sebagai penjelas setiap detik animasi iklan sebagai berikut :

Tabel 2. Animasi Konten Shop Now

\begin{tabular}{|l|l|}
\hline Detik & penjelasan \\
\hline 01.00 & $\begin{array}{l}\text { Elemen visual menjadi bingkai fotografi yang } \\
\text { berganti setiap 01.00 detik dengan teknik keyframe } \\
\text { diberikan fill yang berbeda. Animasi SHOP NOW! } \\
\text { Yang berkedip. }\end{array}$ \\
\hline 02.00 & $\begin{array}{l}\text { Transisi fotografi pada detik 02.00 yang cepat } \\
\text { dengan keyframe dan fill. terlihat web banner yang } \\
\text { sesuai dengan konsep brand yang atraktif dan artsy. }\end{array}$ \\
\hline 03.00 & $\begin{array}{l}\text { Transisi fotografi terakhir terlihat model yang } \\
\text { menghadap kebelakang memperlihatkan desain kaos } \\
\text { yang menjadi ciri khas pada edisi kedua ini menjadi } \\
\text { final content yang menarik. }\end{array}$ \\
\hline
\end{tabular}

Durasi yang digunakan pada iklan web ini berbeda-beda disesuaikan dengan kebutuhan materi yang disampaikan. Dibawah ini uraian durasi yang digunakan untuk publishing iklan web clothing Your Smile is Yours :

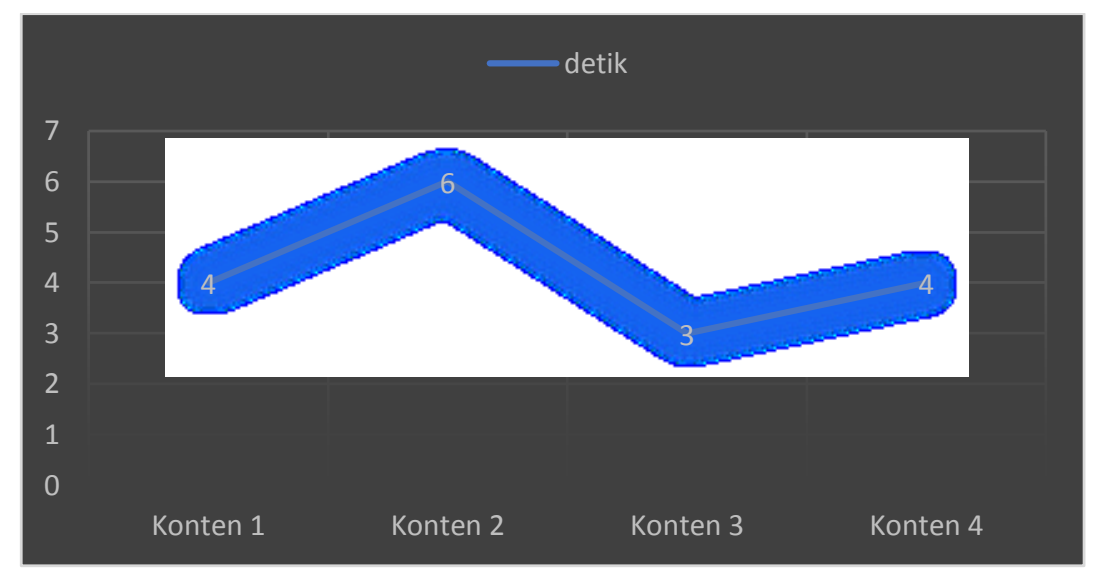

Grafik 1. Durasi iklan web Your Smile is Yours

\subsection{Publishing Web Banner}

Iklan web banner ini memiliki demografi yang sasarannya ke orang remaja hingga dewasa. Media yang cocok untuk publish iklan ini adalah dengan format iklan web banner yang mendukung untuk desktop atau komputer maupun ponsel genggam. Ukuran iklan yang disajikan menyesuaikan pada perangkat yang digunakan (responsive). Salah satu penyedia iklan adsense memiliki pilihan demografi yang dapat disesuaikan dengan 
kebutuhan iklan. Memiliki cangkupan geografis yang luas sehingga dapat menjangkau iklan ke jumlah pengguna. Berikut adalah spesifikasi demografi mengenai iklan web banner clothing Your Smile is Yours :
a. Gender
: Pria dan Wanita
b. Usia
c. Pekerjaan
: $18-25$ Tahun
d. Pendapatan
: mahasiswa, musisi, seniman
e. Lokasi
: Rp.2.000.000 - Rp.5.000.000/bulan
: Solo Raya (Surakarta dan sekitarnya)

Hasil dari metode design sprint merancang desain yang berfokus kepada konsumen agar sesuai dengan target yang diharapkan. Tahap akhir menghasilkan prototype final yang merupakan hasil validate dari beberapa prototype yang telah ditentukan sebelumnya [8]. Iklan web banner ini menjadi media promosi dan informasi di bidang usaha yang berguna sebagai alat yang memberikan kemudahan dalam strategi pemasaran terpadu melalui rancang bangun secara online [9]. Iklan yang telah dirancang dipasang oleh perancang pada web iklan baris di internet, iklan yang ditampilkan pada web adalah beberapa iklan yang tanggal terbitnya pada hari yang sudah divalidasi oleh admin, iklan yang tidak kadaluarsa dan deposit si pemilik iklan cukup diubah menjadi publish untuk membiayai publikasi iklan tersebut [10].

\section{KESIMPULAN}

Sumber internet tidak hanya digunakan untuk memperoleh informasi saja, dengan kata lain dapat digunakan sebagai media untuk melakukan bisnis dengan membangun sebuah website. Mengenai bisnis ini dilakukan penjualan produk seperti, barang-barang berbagai macam roti dan kue, hingga makanan dan minuman, dan lainnya. Sebelum mengenal adanya internet para penjual hanya mengiklankan perusahaan melalui mulut ke mulut. Penyebaran brosur hingga surat kabar sehingga hanya sedikit orang yang mengenalnya. Kini dengan hadirnya internet, kita dapat melakukan bisnis lebih mudah [1]. Berdasarkan hasil yang telah dibahas maka rancang bangun ini menggunakan metode Design sprint pendekatan software Google Web Designer sebagai alat multimedia menghasilkan rancangan web banner yang sesuai implementasi dari konsepnya[11]. Teknik periklanan yang interaktif dan berseries menghasilkan sebuah iklan tentang produk dari brand clothing. Tahap pernacangan menjelaskan hasil prototipe konten web banner dengan menggunakan metode design sprint yang sudah dijelaskan pada metode diatas dan studi kasus yang sudah tertera pada pendahuluan yaitu perancangan iklan web banner tentang clothing pada brand Yours Smile is Yours dengan pendekatan metode design sprint. Konten yang akan dibuat yaitu terdapat 4 (empat) iklan web dengan luaran web banner [12]. Perkembangan di dunia sablon kaos selama ini telah membawa akibat yang cukup pesat dalam dunai usaha. Perusahaan dalam keberadaan sebagai unit organisasi, pada umumnya didirikan dengan tujuan untuk memperoleh keuntungan dengan menyediakan barang dan jasa yang sesuai dengan kebutuhan masyarakat [13]. Publishing web banner melalui penyedia iklan adsense memiliki pilihan demografi yang dapat disesuaikan dengan kebutuhan iklan. Memiliki cangkupan geografis yang luas sehingga akan dapat menjangkau iklan ke jumlah pengguna. Metode design sprint dibagi menjadi 2 (dua), design sprint planning dan design sprint phases and methods. Design Sprint menghasilkan kerangka kerja dan metodologi yang digunakan sangat fleksibel sehingga terus mengadaptasi untuk perancangan iklan web banner dengan menggunakan poin utama Google Web Designer yang memiliki fitur aplikasi gratis pembuat HTML5 dan AMPHTML yang berfitur lengkap serta memiliki antarmuka visual dan kode yang sudah terintregrasi dengan produk Google dan platform iklan lainnya. Berfitur lengkap serta memiliki antarmuka visual dan kode yang sudah terintregrasi dengan produk Google dan platform iklan lainnya, sehingga dapat menghubungkan data, menyederhanakan alur kerja dan berkolabirasi dengan tim lain.

\section{REFERENCES}

[1] V. M. M. Siregar, "Perancangan Website Sebagai Media Promosi Dan Penjualan Produk," TAM (Technology Accept. Model., vol. 9, no. 1, pp. 15-21, 2018.

[2] A. H. B. M. S. Nurmana and T. A. Wibowo, "DESAIN SITUS WEB SEBAGAI MEDIA INFORMASI DAN PROMOSI PADA ESSY'S BROWNIES SEMARANG,” vol. 12, no. 2, pp. 1-12, 2018.

[3] P. Diploma, I. I. I. Jurusan, D. Komunikasi, F. Seni, R. Dan, and U. S. Maret, "PERANCANGAN MEDIA PROMOSI CLOTHING RACING SPEEDLINE,” 2018.

[4] O. Zedadra et al., "Analisis Tingkat Penjualan Sablon Kaos Ditinjau dari Kualitas Pelayanan dan kualitas Produk pada CV. Rockaballer Tahun 2017/2018” Sustain., vol. 11, no. 1, pp. 1-14, 2019,

[5] A. Putra, Y. Tama, F. I. Kreatif, and U. Telkom, "PERANCANGAN VISUAL WEBSITE E-COMMERCE USE 


\section{CLOTHING SEBAGAI MEDIA TRANSAKSI , INFORMASI DAN PROMOSI,” pp. 1-8.}

[6] T. Akhir, "PERANCANGAN ULANG DESAIN APLIKASI ' TEMAN BUMIL ' DENGAN METODE DESAIN SPRINT ( STUDI KASUS PT . GLOBAL URBAN ESENSIAL ),” 2020.

[7] A. Prasetyo, H. M. Az-zahra, and A. H. Brata, "Perancangan Aplikasi Bimbingan Skripsi Berbasis Mobile dengan menggunakan Pendekatan Design Sprint ( Studi Kasus Bimbingan Skripsi Fakultas Ilmu Komputer Universitas Brawijaya )," J. Pengemb. Teknol. Inf. dan Ilmu Komput., vol. 3, no. 6, pp. 5808-5816, 2019, [Online]. Available: http://j-ptiik.ub.ac.id/index.php/j-ptiik/article/download/5581/2633/.

[8] Pratama, “Analisis dan Perancangan User Interface/User Experience dengan Metode Google Design Sprint dan A/B Testing Pada Website Startup Qtaaruf," Director, vol. 15, no. 40, pp. 6-13, 2018, [9] I. Yuniva and D. Hestiyanto, "Vol 4 No 1 - Februari 2018," vol. 4, no. 1, pp. 24-33, 2018.

[10] M. Sukarsa and G. M. Rupayana, "Rancang Bangun Web Iklan Berbasis Mobile,” Lontar Komput. J. Ilm. Teknol. Inf., vol. 2, no. 1, 2012, doi: 10.24843/LKJITI.

[11] A. S. Patria and N. Kristiana, "Pengembangan Desain Sablon Kaos Berbasis Seni Budaya Nusantara," 2018, doi: 10.31219/osf.io/u38eh

[12] R. D. Indahsari and A. Sugiarto, "Perancangan Media Promosi pada Smile Island Digital Printing Menggunakan Website," J. Desain Komun. Vis. Asia, vol. 1, no. 1, p. 44, 2017, doi: 10.32815/jeskovsia.v1i1.310.

[13] A. Rahman, H. Aryanto, and A. Christianna, "Perancangan Media Promosi Produk Fashion dari Pengelolaan Limbah Fashion," J. DKV Adiwarna, vol. 1, no. 14, p. 8, 2019, [Online]. Available: http://publication.petra.ac.id/index.php/dkv/article/view/8632/7792. 